\title{
Estabelecendo relações entre as práticas e condições de lazer no bairro Jardim Borborema
}

\author{
Heluan Ruana Alves de Medeiros \\ Cheng Hsin Nery Chao
}

\section{SciELO Books / SciELO Livros / SciELO Libros}

LEMOS, EMBC., DANTAS, ER., and CHAO, CHN., orgs. De portas abertas para o lazer: a cultura lúdica nas comunidades de Bairro [online]. Campina Grande: EDUEPB, 2009. 184 p. ISBN 978-85-

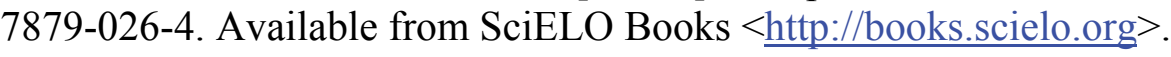

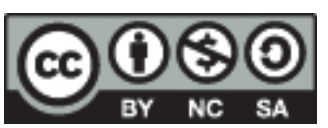

All the contents of this work, except where otherwise noted, is licensed under a Creative Commons Attribution-Non Commercial-ShareAlike 3.0 Unported.

Todo o conteúdo deste trabalho, exceto quando houver ressalva, é publicado sob a licença Creative Commons Atribuição Uso Não Comercial - Partilha nos Mesmos Termos 3.0 Não adaptada.

Todo el contenido de esta obra, excepto donde se indique lo contrario, está bajo licencia de la licencia Creative Commons Reconocimento-NoComercial-CompartirIgual 3.0 Unported. 


\title{
Estabelecendo relações entre as práticas e condições de lazer no bairro Jardim Borborema
}

\author{
Heluan Ruana Alves de Medeiros \\ Cheng Hsin Nery Chao
}

Ao propor uma abordagem voltada para o lazer no bairro Jardim Borborema, zona sul da cidade, buscamos conhecer e analisar o mesmo, estabelecendo as relações entre o lazer, saúde e educação, através de suas organizações, espaços, equipamentos e manifestações culturais.

O bairro possui uma singularidade que o diferencia em termos de características físicas, pois possui áreas urbanizadas, áreas rurais e ainda, áreas mistas: urbano/rural. Não se podendo generalizar as análises dos espaços de lazer como se fossem todos iguais.

Conforme Freitag (2006), devido à população não está tão atenta e ativa na exigência de seus direitos, o poder público acaba fazendo vistas grossas e perpetuando momentos em que a cidade passa a ser local de verdadeira barbárie, não havendo investimento nestas necessidades em muitos bairros. No caso do Jardim Borborema, percebemos que os representantes de bairro procuram garantir os direitos da população, porém é um processo lento que necessita vencer os caminhos burocráticos que se estendem ao longo dos anos.

A elaboração de políticas públicas de lazer pode ocorrer cada vez mais de modo interdisciplinar. Apesar de existirem questionamentos sobre o porquê do lazer sempre estar relacionado a outro fator, Leila Pinto (2008, p. 4) explica que 
A convergência de esforços, as alianças estratégicas, as redes de ações intersetoriais, compartilhadas, são essenciais para potencializarmos resultados significativos no sentido deste pacto estabelecido. No campo do lazer essa aliança é essencial, pois as ações do lazer não apenas podem potencializar a sua conquista como direito, como podem também contribuir efetivamente para a conquista de outros direitos, como saúde, educação, cultura, preservação ambiental, turismo, convivência com segurança, dentre outros.

Através dos direitos fundamentais de todo cidadão citados acima, atingem-se as funções sociais e bem-estar, que estão estreitamente ligados ao desenvolvimento humano e transformação social.

\section{Jardim Borborema: conquistas e relações, lazer, saúde e infraestrutura}

O Jardim Borborema é um bairro localizado na zona sul da cidade de Campina Grande com 3.883 habitantes (IBGE, 2002). Tem como bairros vizinhos: o Cruzeiro e Presidente Médici(N); Distrito Industrial (L), Acácio Figueredo (0). Os conjuntos Ressurreição e Jardim Vitória compõem esta comunidade.

0 bairro faz parte da periferia de Campina Grande, sendo marcado pela criminalidade, falta de infraestrutura e saneamento básico. Marcellino (2008, p.15) diz que o aumento da população urbana não foi acompanhado pelo desenvolvimento da infraestrutura, "gerando desníveis na ocupação do solo e diferenciando marcadamente, de um lado as áreas centrais, concentradoras de benefícios. E de outro a periferia, verdadeiro depósito de habitações".

Isso é o que ocorre na zona urbano/rural do Jardim Borborema, é um "depósito de habitações". Não identifica-se em todo bairro uma praça pública sequer, não há quadras esportivas de livre acesso ou qualquer outra área pública definida para o convívio social, fora a SAB e o calçadão da Avenida Juscelino Kubitschek que atravessa o bairro. 
Não se sabe muito sobre sua história, moradores com mais de 15 anos, no bairro, relatam que, há cerca de duas décadas, noventa e duas (92) casas foram cedidas para o mesmo número de famílias. Estas haviam perdido suas casas numa enchente e foram abrigadas no Estádio de Futebol da cidade, Governador Ernani Sátiro (0 Amigão), até a entrega de suas novas casas pela Prefeitura. Parte do conjunto Ressurreição foi ocupado por alguns garis da prefeitura que se inscreveram para concorrer e foram sorteados. Os ganhadores receberam o terreno e cada um se responsabilizou pela construção de sua casa.

A ex-presidente da associação de moradores, do conjunto Ressurreição mais especificamente, e moradora do bairro, passou-nos uma história de luta em comunidade para erguer a igreja. A doação do terreno foi o pontapé inicial para a construção, que fica no conjunto Ressurreição. Todo o restante da população contribuiu como pôde. Os mercadinhos próximos ajudavam e eram realizadas várias atividades para angariar fundos para a construção da Igreja.

Era realizado um verdadeiro mutirão. Segundo Gabriel (2008, p.65), “a modernidade, de fato, é caracterizada por uma redução da capacidade festiva, pela privação de certos hábitos coletivos de celebração e a progressiva individualização de alguns aspectos da vida em detrimento do coletivo", no entanto a comunidade Jardim Borborema mantém sua tradição cultural religiosa ativa.

O bairro possui várias igrejas que funcionam como canais institucionais do bairro. Cada qual com seus princípios tem influência nas ações de envolvimento e desenvolvimento da comunidade. É por meio de suas festas tradicionais que as comunidades estreitam seus laços e mantêm sua identidade como grupo, celebrando também sua vida cotidiana.

A grande maioria destas manifestações culturais religiosas proporciona o lazer. São atividades como bingos, feiras de roupa, festival de sorvete, serestas, feijoadas, rifas, São João, além da festa do padroeiro realizada em abril com a novena e três dias de comemoração com shows e comidas típicas.

A Associação de Moradores tem outras histórias de luta junto à comunidade. Conseguiu levar um Posto de Saúde da Família, iluminação, 
calçamento (em algumas ruas), saneamento básico na parte urbana do bairro, alfabetização para adultos além de vários cursos profissionalizantes para a comunidade.

Cada vez mais o Bairro cresce com ajuda da população através de associações representativas, como SAB e Associação de Moradores, que são bastante atuantes, objetivando sempre o atendimento às reivindicações dos moradores através de seus representantes. "Os moradores organizados vão se reconhecendo enquanto sujeitos sociais, capazes de projetar autonomamente suas práticas, processo que é contínuo, inacabado, diante das incessantes forças que tensionam para formas mais heterônomas de relações sociais" (MÜLLER, 1992).

A população sente a falta de políticas públicas de lazer e reclama que se houvesse incentivo neste sentido não haveria tanta droga e criminalidade no bairro. "O Lazer ocuparia o tempo em que estão aprontando das suas", fala um morador triste com a realidade.

Quanto à saúde, muitos associam ao lazer, primeiro por boa parte praticá-lo através de atividade física, segundo por trazer a sensação de bem-estar. Lamenta-se a falta de saneamento básico, infraestrutura, que faz com que crianças realizem suas atividades de lazer, seu brincar, em espaços com esgoto à céu aberto e junto dos animais que se encontram soltos no bairro.

A barbárie apontada no início do texto, baseando-nos em Freitag (2006), diz respeito justamente à falta de áreas públicas de lazer. As crianças que querem jogar bola têm que dividir o espaço com jumentos, bois, cavalos, a ponto de muitas já apresentarem carrapatos em suas roupas, como relata a assistente social responsável pelo Pro-Jovem Adolescente no bairro. 


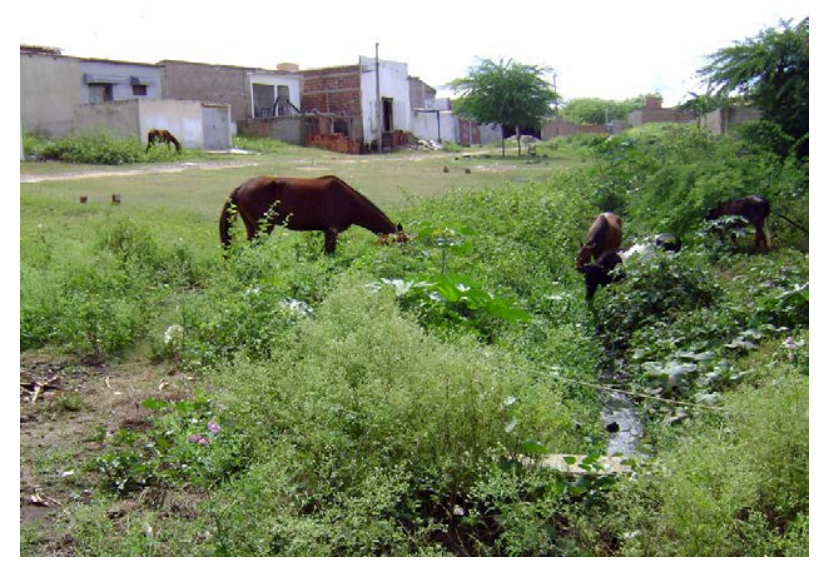

Imagem 01: Espaço utilizado por crianças para brincar

Fonte: Arquivo GCEM

A Unidade Básica de Saúde da Família, quando os pesquisadores foram a campo estava passando por reforma e funcionando temporariamente em uma sala da SAB. O PSF tem sua participação no lazer da comunidade, como coloca Yara Carvalho (2008, p.113):

\begin{abstract}
O lazer pode ter na atenção básica e no PSF um espaço interessante para compor com o cuidado e a atenção em saúde. O espaço e o tempo do lazer podem ampliar as possibilidades de encontrar, escutar, observar e mobilizar as pessoas adoecidas para que no processo de cuidar do corpo elas efetivamente construam relações de vínculo, de co-responsabilidade, autônomas, inovadoras e socialmente inclusivas(...).
\end{abstract}

Numa relação mútua de benefícios entre saúde e lazer, vê-se a necessidade de uma maior atuação do PSF junto à comunidade, já que esta deve "valorizar e otimizar o uso dos espaços públicos de convivência e de produção de saúde" (CARVALHO, 2008, p.113).

A Unidade Básica de Saúde da Família do bairro disponibiliza o espaço fora do horário de expediente para as reuniões do Clube de Mães, que ainda não tem sede. Durante a pesquisa de campo, como o PSF esta- 
va em reforma, as reuniões do clube de mães estavam sendo realizadas num pequeno terraço em frente da casa da presidente.

\section{A organização da comunidade gera força nas reivindicações e ações sociais}

A SAB foi fundada em 1986, o atual presidente já está na liderança, há sete anos, eleito e reeleito após a morte do fundador. Junto à presidência estão mais dez sócios na gestão, entre eles o vice-presidente, secretários, tesoureiros e cinco pessoas da fiscalização. A SAB conta com a contribuição mensal na quantia de dois reais $(\mathrm{R} \$ 2,00)$ de cerca de 600 sócios e os próprios moradores se envolvem com o trabalho voluntário nas atividades da sociedade.

Quando se fala em parcerias é com grande satisfação que o presidente fala do crescimento nos diversos aspectos, inclusive na questão visual da unidade com a pintura, mas afirma que:

a maior preocupação nossa aqui, era de capacitar as pessoas para o mercado de trabalho, certo? E aí fizemos uma parceria primeiro, primeiro com o Governo do Estado na reforma, em seguida parceria com o SENDAC, que eles têm vários cursos profissionalizantes para os jovens, para mulher, pra o adulto, qualquer pessoa que queira fazer acima de 16 anos. Em seguida nós fizemos parceria também com o SENAC, SENAI e a FINEP, também que pertence ao Governo do Estado. E agora nós estamos fechando um acordo entre SENAC e Redentorista, e também como, fiz também aqui com uma parceria com a UEPB que foi o ambulatório itinerante que o ano passado tivemos duas vezes aqui.

Na fala acima, podemos notar a busca por várias parcerias, isso pode mostrar a pouca atenção e destinação de verbas pelo poder público e desta forma, a necessidade por diferentes fontes de renda.

A SAB é uma conquista do bairro assim como também trouxe benfeitorias para o mesmo, como lembra o presidente que "conseguiu através da SAB muitas coisas, muitos benefícios, principalmente a ener- 
gia que não tinham... É luz, água, transporte, tudo foi uma luta muito grande".

"A participação cidadã não deve ser encarada pelos governantes como uma concessão, mas um direito do cidadão"(MARCELLINO, 2001). Esta afirmação implica na co-gestão entre organizações comunitárias e o poder público, onde a iniciativa da população e o financiamento do governo integrados trarão o resultado final.

A Sociedade Amigos do Bairro (SAB), Associação de Moradores e Clubes de Mães são parte da representatividade de uma comunidade através da qual é possível através de reuniões e assembleias discutir o que é melhor para o bairro, para assim, identificar soluções e reivindicar ao poder público. Como na SAB do Jardim Borborema uma vez por mês realiza:

a assembléia geral onde convidamos todos os moradores, sócios ou não, para participar. (...) A gente tem um papel muito importante, principalmente, como se diz, em orçamento participativo, a SAB tem por direito de participar do orçamento para que traga os benefícios para nossa comunidade (Presidente da SAB)

Apesar de comentar sobre as necessidades relacionadas ao lazer, percebe-se uma maior facilidade em oferecer capacitação profissional aos moradores do bairro. E fala que tem como principal função, a social:

Integrar as pessoas à comunidade, juntar e criar pontes para criar reivindicações, principalmente na área de lazer que nós não temos, é cultura também que infelizmente nosso povo é muito atrasado, também com o profissionalismo. (Presidente da SAB)

Junto às parcerias ofereceram cursos de confecção de calçados, recepcionista, corte e escova, corte e costura, macramê, crochê, pintura em tecidos, de doces e salgados e curso de favo de mel, este último com recursos próprios. Cursando e praticando o que aprendem, estas pessoas, que, na maioria, são as donas de casa, sentem-se mais úteis para os outros e acima de tudo para si mesmas, visto que fazer, ou pelo menos deveriam fazer, por livre e espontânea vontade podendo 
ser considerado um momento de lazer, por oferecer um momento de socialização, aprendizado, criatividade e produtividade.

É visto um trabalho sério e dedicado por parte dos gestores para ajudar a comunidade, lamenta-se o fato de não enviarem projeto por não saber redigir um. 0 presidente e seu vice afirmam já ter enviado oficio solicitando algum curso e expondo as ideias à prefeitura. 0 mais interessante foi a espera de um treinamento em gestão a ser oferecido pela Universidade Federal de Campina Grande - UFCG. Com isso poderiam pôr as ideias em um projeto bem estruturado e enviar aos poderes públicos.

No âmbito do lazer, pensam mais na questão de uma área que possa oferecer práticas físicas, neste almejam um lugar onde os moradores pudessem praticar a natação, o vôlei, o futebol. Também desejam uma sala de informática, na qual possam oferecer o curso.

Segundo a presidente do Clube de Mães, algumas áreas já foram definidas pela prefeitura há algum tempo, contudo, o interesse político tem trazido barreiras para a edificação destes locais. Ainda percebe-se a questão político partidária-influindo nas conquistas dos direitos dos moradores, pois os líderes comunitários, muitas vezes, precisam se tornar verdadeiros cabos eleitorais para ter suas reivindicações atendidas, caso seu candidato ganhe.

\section{A Escola: as parcerias precisam caminhar juntas}

Das 88 escolas da rede municipal de ensino encontradas na zona urbana da cidade, três (03) se encontram no bairro em estudo. A escola onde foi realizada a pesquisa trata-se de um Centro Educacional de Atividades Integradas - CEAI Antônio Marques da Silva Mariz, fundado em 1995. A escola tem parceria com o Instituto Alpargatas ${ }^{1}$ no Projeto de Educação por Meio do Esporte.

10 Instituto Alpargatas investe na capacitação continuada dos profissionais da Educação, promove concursos de instrumentos didático-pedagógicos para tornar as aulas mais atrativas e fornece às escolas os recursos e equipamentos necessários à aplicação dos projetos (Instituto Alpagatas). 
Com esta parceria, a escola reduz o custo com os equipamentos para a prática das atividades desportivas, a Alpargatas arca com o material necessário, "bolas, uniformes, tênis certo, todo o material esportivo né? Rede, essas coisas" (diretora). Isso poderia ajudar os alunos a se interessarem e se envolverem mais com a escola, e assim, de certa forma não serem tão influenciados pelas más companhias na rua. No entanto, não é bem o que acontece, há falta de manutenção do espaço e dedicação profissional.

A escola tem boa estrutura física, mas carece de cuidados. Na verdade, precisa é de uma reforma mesmo. São tomadas de energia expostas e ao alcance das crianças, quadra sem traves e postes, refeitório com bancos sem assento, paredes descascadas e furadas por balas de revólver, estes, dentre outros fatores preocupam a segurança dos alunos da escola.

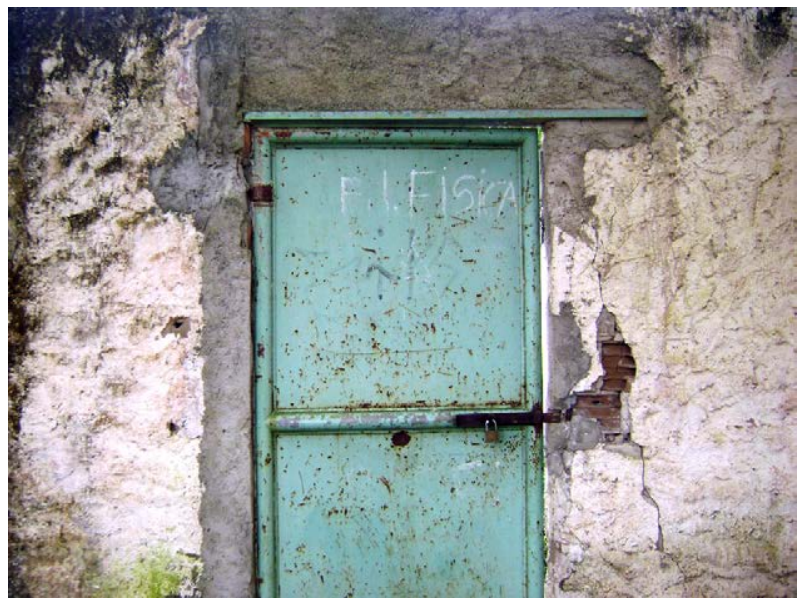

Imagem 02: Parede furada por projéteis com passagem para área de práticas físicas.

Fonte: Arquivo GCEM 


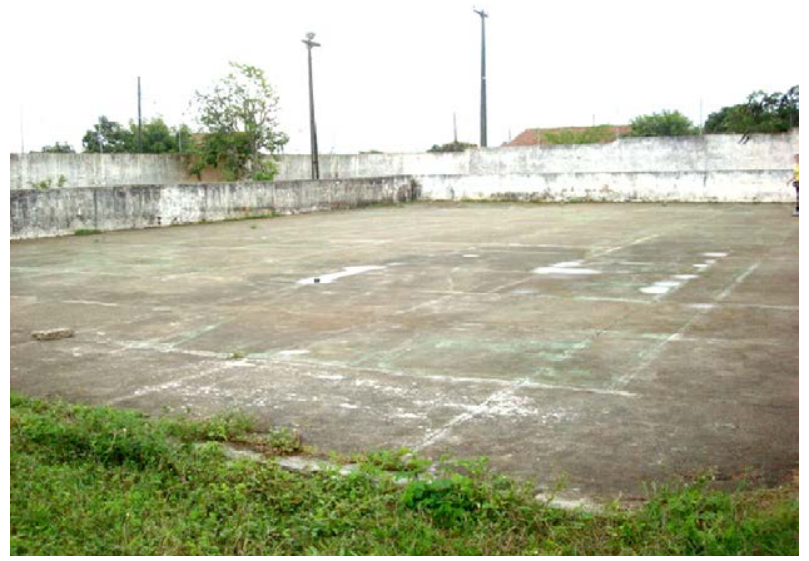

Imagem 03: Quadra poliesportiva

Fonte: Arquivo GCEM

Quanto às atividades realizadas, a entrevistada relata os seguintes fatos:

Esses meninos só conhecem bola, [...] esqueceram muito o lado lúdico né, a parte recreativa, alguns jogos como antigamente, na hora do recreio os meninos só brincam de correr, aí vem aquela coisa que poderia justamente, se tivesse uma outra parte recreativa, envolvê-los não é, como antigamente não é, que a gente trabalhava o quê né, a gente via amarelinha, a gente via o pula corda, a gente via o bambolê[...] 0 recreio aqui é absurdo, é tapa, é beliscão, é pancadaria, uma violência incrível, sabe. E eu acho que se fosse trabalhado bem essa parte recreativa, as crianças tinham mais afeto às regras, porque disciplina é regra, e eles não têm o hábito de obedecer, de ter limites, e é só saber lidar com essa falta de limites da família (Diretora).

No relato da diretora da escola, vemos que os investimentos feitos pelo Instituto Alpargatas ainda não surtiram efeito, e cita a falta de investimento nas atividades recreativas de cunho educativo, trabalhando essencialmente o esporte competitivo. 
Entendendo a recreação como parte prática, vivencial e que está presente na formação do indivíduo, vê-se a preocupação das instituições de ensino em proporcionar essa prática aos seus alunos já que, como considerada por Marcellino (2008), a recreação é veículo e objeto de educação, considerando além das possibilidades de descanso e divertimento a de desenvolvimento pessoal e social, ainda assim é fundamental que seja uma atividade de caráter desinteressado, não tendo os benefícios trazidos como foco e sim a vivência.

\section{Reconhecimento de espaços e interesses de lazer no bairro e ações de manifestação cultural}

O lar é o principal equipamento não-específico, este é "um dos poucos equipamentos, disponíveis para grandes parcelas da população "empurradas" para dentro de suas casas no tempo disponível para o lazer. Exatamente essas pessoas têm condições para o desenvolvimento do lazer nas suas habitações" (MARCELLINO, 2008, p.17).

Existem dois locais com equipamentos específicos de lazer no bairro: a Associação de Cabos e Soldados, que é restrito aos cabos e soldados associados; e o Clube dos taxistas é aberto à comunidade mediante pagamento. São lugares onde a população pode utilizar para o lazer explorando interesses como: social e físico não só durante os fins de semana, quando os clubes são abertos, mas também quando alugados, já que os mesmos oferecem essa possibilidade para comemorações de aniversários e casamentos, shows e confraternizações. Não sendo esta a principal finalidade destes, trata-se de instituições corporativas, que são orientadas para a defesa política de interesses setoriais ou grupais (sindicatos ou associações de classe ou de região) ou para o consumo coletivo (clubes) (PEREIRA; GRAU, 1999).

As práticas de lazer necessitam de espaços para fortalecer as relações com os sujeitos, causando satisfação pessoal, pois o fato de ocupar um espaço significa a necessidade de estar subordinado a alguns conteúdos culturais. Veremos a seguir algumas das atividades de lazer 
que acontecem, no bairro, ligadas aos seus interesses, seja ele social, físico, intelectual, manual e/ou artístico (DUMAZEDIER, 1980).

Numa visita ao bairro, foi possível encontrar crianças utilizando um terreno baldio para empinar pipa, jogar futebol, pedalar bicicletas, além de vizinhos, nas calçadas, conversando e observando o que acontece na rua. Mesmo violento, o bairro tem vizinhos amigáveis e oferece espaço para realização de tais atividades, seja na casa ou calçada do amigo, num bar ou em reuniões de SAB ou Igreja.

A igreja tem um papel muito importante na comunidade, pois como mencionamos anteriormente, realiza várias atividades que proporcionam o lazer. Há quatro anos que em abril é realizada a festa do padroeiro da comunidade, uma semana toda é dedicada a ele - dos sete dias, três são com festa oferecida à comunidade.

Em junho, na cidade do Maior São João do Mundo, não podia faltar nossa querida comida típica. São agendados dois dias para comemorar, a pamonha, a canjica, o milho assado e cozinhado, tudo feito pelos moradores para vender e arrecadar fundos para a igreja. De toda forma é um trabalho voluntário e gratificante para os que participam e está dentre outras vivências supracitadas inserido no interesse social. O presidente diz que "Todo ano eu tenho obrigação de trazer quadrilhas juninas pra se apresentar no nosso bairro no mês de junho".

Em setembro, é realizado o Festival do Sorvete, beneficiando principalmente as crianças, já foi fechada a rua para que fossem feitas brincadeiras na mesma. A SAB também sempre relembra datas comemorativas como Dia das Mães, o Dia dos Pais e Dia das Crianças.

O Jardim Borborema Fest é um Festival de bandas marciais que ocorre na própria rua, é o grande evento realizado pela $\mathrm{SAB}$, o mesmo conta com a participação da massa na comunidade "Nós já vamos para o terceiro ano, este ano, é do Jardim Borborema Fest. Cada ano vem crescendo o evento, graças a Deus é um sucesso, esse ano foi maior do que os outros anos. Todo mês de agosto a gente faz essa manifestação." (Presidente da SAB).

A criminalidade em parte do bairro já é conhecida, subtende-se que a decisão também tenha ocorrido "por conhecer o comportamento 
de certos moradores. A grande dificuldade apontada pelo gestor é na área de comunicação, que nem sempre a gente tem a comunicação ao nosso favor.(...) o pessoal adora a participação."

A escola relata um antigo Jornalzinho, no bairro, um ano atrás, hoje não encontramos nenhum veículo de comunicação sobre os informes internos do bairro. Este foi editado durante um ano por estudantes estagiários do curso de comunicação social da UEPB. Hoje a divulgação da maioria do que há na comunidade para a comunidade é feita através de carros de som ou panfletos.

O Bairro dispõe de uma extensa pista de caminhada (calçada da Av. Juscelino Kubitschek) que alcança também o bairro do Cruzeiro. Esta é a que deixa mais evidente a relação saúde e lazer. A caminhada além de promover a saúde, também, traz a sensação de bem-estar, muitos vão com amigos, se não vão, encontram a vizinhança. É um equipamento onde é possível ver pessoas de todas as idades e remete-se aos interesses físico e social.

São nas atividades de interesses físicos que encontramos pessoas interessadas na promoção de saúde, seja esse intuito para evitar doenças futuras, na recuperação de algo já detectado, ou no benefício desinteressado (BAGRICHEVSKY; ESTEVÃO E PALMA, 2003).

Em apoio às atividades realizadas, no local, a prefeitura Municipal da cidade realiza o projeto Campina Bem-estar ${ }^{2}$ que visa "promover a prática de atividades físicas de forma planejada e eficiente, como forma de melhorar as condições de saúde da população, através da realização de uma avaliação física das pessoas que costumam fazer caminhadas sem qualquer acompanhamento" (Prefeitura Municipal de Campina Grande, 2008).

2 Dentro das ações rotineiras de saúde são realizadas aferições de pressão arterial, avaliação física (com verificação de peso, altura, freqüência cardíaca, medição de percentual de gordura corporal e índice de massa corporal). 


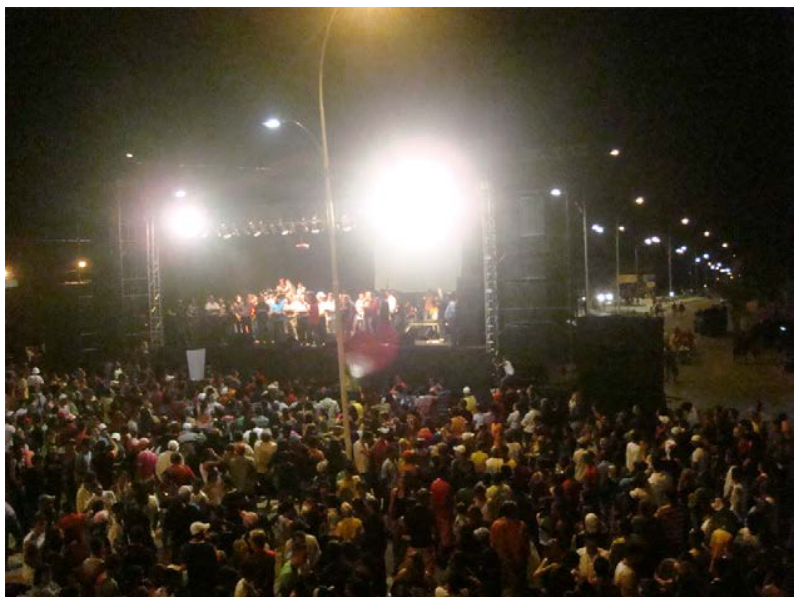

Imagem 04: Inauguração da pista de caminhada da Av. Juscelino Kubitschek em 08 de maio de 2009.

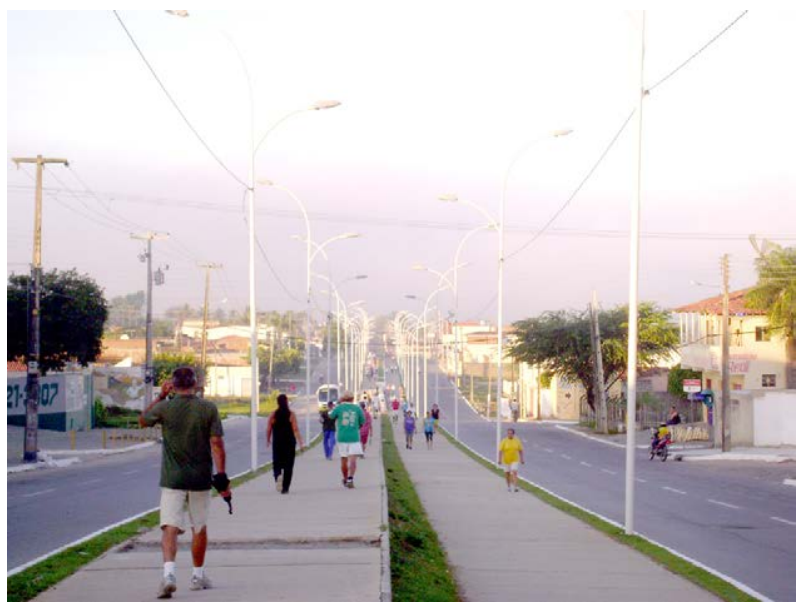

Imagem 05: Pista de caminhada - zona urbana Fonte: Arquivos GCEM 
A construção da pista também serve de incentivo e dá oportunidade à comunidade de estar realizando um novo evento, em 01 de maio de 2009, em comemoração ao Dia do Trabalho, a SAB do Jardim Borborema promoveu a $1^{a}$ c corrida e Passeio Ciclístico do Trabalhador.

A SAB em parceria com a UEPB já ofereceu as instalações para que fosse realizado um projeto de Extensão que proporcionasse atividades físicas orientadas à comunidade. 0 presidente diz que a maior clientela no projeto, que era realizado nas segundas, quartas e sextas, eram as idosas moradoras do bairro.

A rua e terrenos baldios encontrados, no bairro, são outro espaço de lazer, mais visto sendo utilizado pelas crianças, em um deles observaram-se crianças reunidas para o futebol, esporte recreativo mais encontrado, talvez por não precisar de muitos equipamentos, para eles com uma bola e quatro pedras "está tudo certo". Foram vistas, também, crianças pedalando bicicleta, empinando pipa.

A quadra da escola do bairro, apesar da falta de manutenção é um dos únicos equipamentos específicos do esporte recreativo. Quanto à utilização por parte da comunidade, a diretora respondeu que "Ela é aberta a comunidade nos finais de semana" com exceção dos horários em que ocorre "o projeto capoeira [...] que o município tem contrato com alguns professores de capoeira, que também é um esporte e no sábado acontecem essas aulas de esporte de capoeira para os alunos que não podem ir durante a semana".

O Jogos Internos fazem parte do lazer da maioria da população, pois os alunos se divertem, estejam jogando ou torcendo juntamente com os familiares e amigos. Um morador do bairro relata que, há cerca de cinco anos, existiam oito times de futebol, hoje tem conhecimento de apenas um, diz também que, quando a quadra era cedida à associação de moradores, promovia até campeonatos entre as equipes.

Tratando-se dos espaços de interesses intelectuais de lazer, podemos perceber a existência, tanto na escola quanto na $\mathrm{SAB}$, de bibliotecas, que são uma opção, mesmo que limitada, já que a escola é que determina o horário que irão até a mesma, e a SAB carece de recursos humanos para trabalhar com a sua. A SAB já contou com o apoio de 
uma voluntária, esta saiu por conseguir um trabalho. Desde então, não encontraram quem continuasse com os serviços.

A busca contínua por quem desenvolva atividades utilizando e assumindo a biblioteca mostra mais uma vez o interesse em facilitar o acesso da comunidade ao mundo das letras, ao conhecimento e leituras edificantes que sejam vistos não só como necessidade escolar, mas como o crescimento desobrigado.

'O Pró-Jovem, programa do Governo Federal em parceria com o município, usa sala da SAB para as atividades que envolvem jovens do Jardim Borborema e bairros vizinhos. 0 grupo também tem acesso à biblioteca, mas ainda sente necessidade de um espaço maior para realizar as atividades recreativas, que se realizam uma vez por semana.

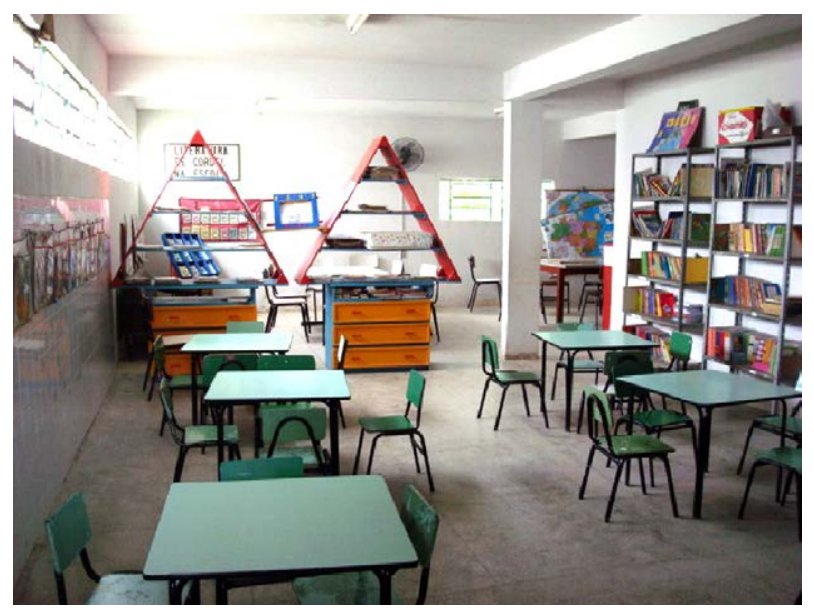

Imagem 06: Biblioteca da escola 


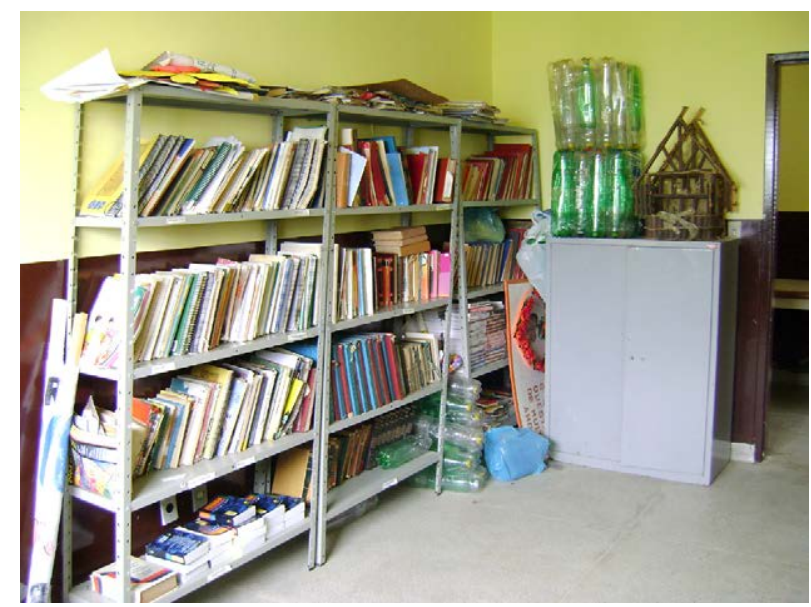

Imagem 07: Biblioteca da $\mathrm{SAB}$

Fonte: Arquivos GCEM

Existem lan houses, bem frequentadas, ou mesmo internet em casa. Como já mencionado, a SAB pensa em montar um laboratório de informática, a escola também tem sua sala de informática pronta, no entanto, faltam os computadores, para que assim a comunidade possa desfrutar do que a tecnologia oferece.

Por ser um bairro de limite com a zona rural, é possível observar muitas criações de animais em "quintais" de área verde e currais em meio às casas. Desta maneira formam-se ruas sem planejamento, infraestrutura e rede de esgoto. 0 que dificulta na implantação de políticas públicas de lazer e saúde. 


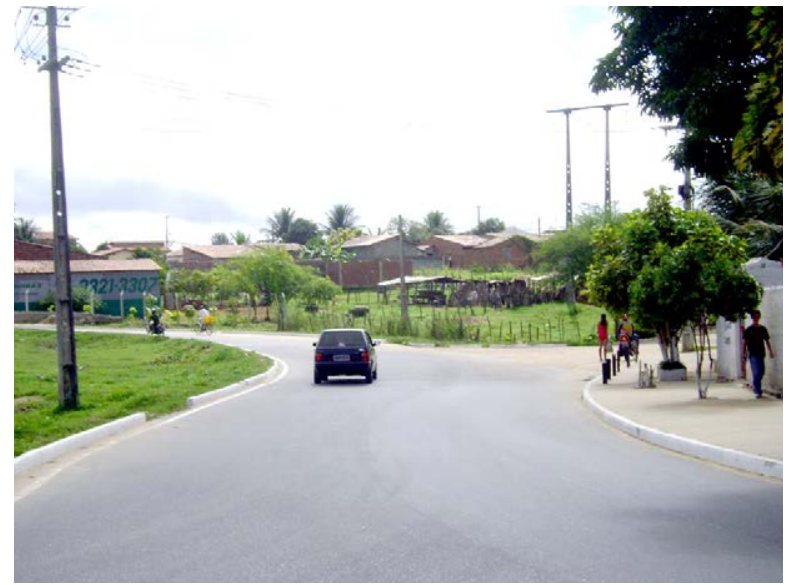

Imagem 08: Interface zona urbano/rural

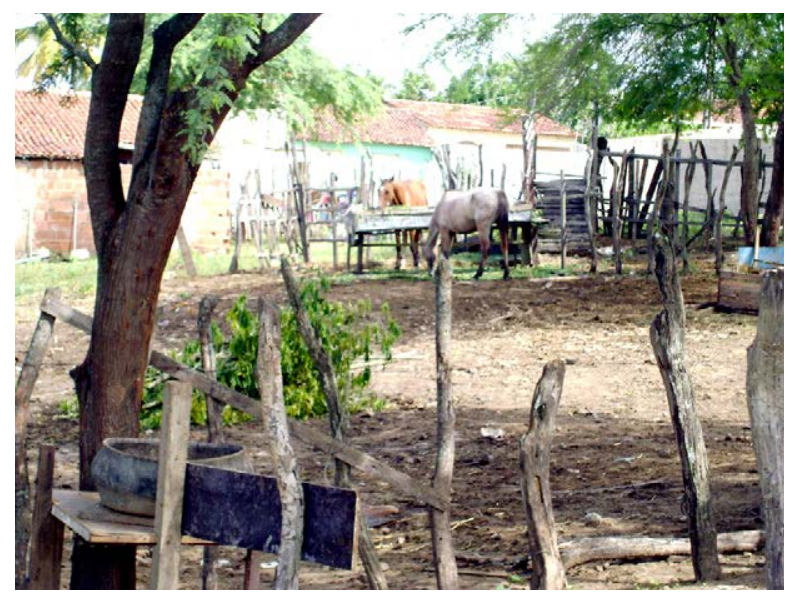

Imagem 09: Zona rural

Fonte: Arquivos GCEM 
Em meio à situação, a escola aproveita a oportunidade de lidar com a consciência ambiental. A unidade é bem arborizada e tem programas de ação ambiental realizados com profissional responsável por tudo da área. Junto aos alunos, ela cuida de uma horta onde cultivam o que pode ser utilizado na preparação da merenda. Também mudas de diversas árvores são cuidadas por eles.

No trabalho ecológico da escola, as crianças usam sua criatividade com sucata para embelezar o ambiente onde ficam as plantas. Este está inserido nos interesses manuais, por ser feito através da manipulação em sua forma plena (DUMAZEDIER, 1980). Como também é notável a falta de reforma ou manutenção na escola, como pintura, os alunos foram convidados a usar sua imaginação e expressar sua criatividade em paredes da escola na prática dos interesses artísticos, gerando encantamento, mostra uma sensação de quem o produz, universo estético feito de imagens e emoções, de sentimentos e imaginário (DUMAZEDIER, 1980).

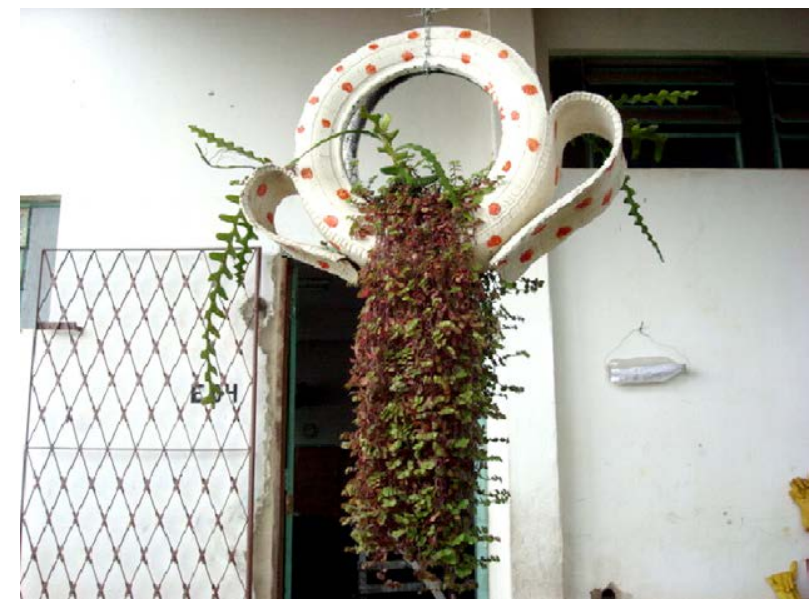

Imagem 10: Xaxim de material reciclado trabalhado artisticamente 


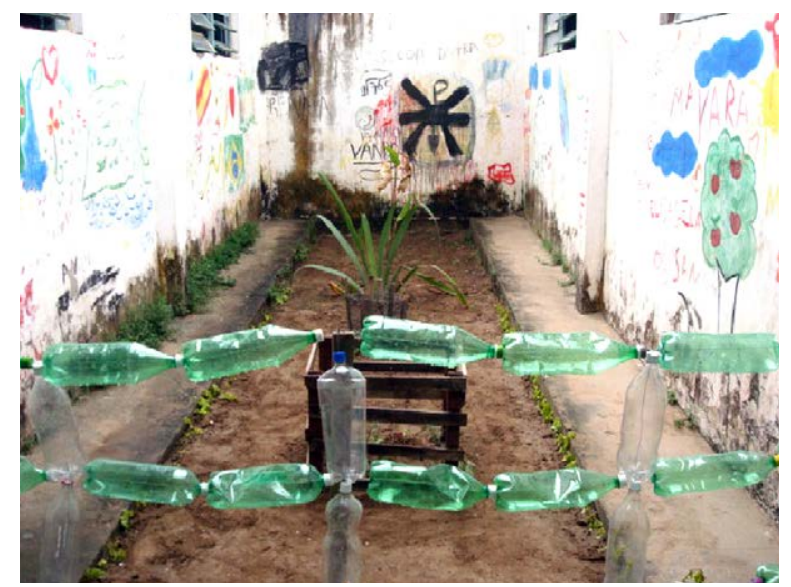

Imagem 11: Espaço revitalizado com arte em grafite e cerca de material reciclado

Fonte: Arquivos GCEM

A SAB oferece cursos que exigem criatividade e trabalho manual, como de pintura, corte e costura e no bordado. Também é desenvolvido um trabalho em parceria com a prefeitura para atender às pessoas especiais. 0 trabalho conta com assistente social, pedagogo e psicólogo. Os encontros realizados uma vez por semana oferecem assistência especializada para promover o bem-estar e crescimento pessoal destes.

Como observado no bairro, a rua é um importante espaço de lazer. Nela, as crianças brincam, são realizadas festas e festivais. Desta forma, o imaginário e a livre expressão ganham vida e enriquecem as experiências.

\section{Considerações finais}

O Bairro Jardim Borborema, apesar de pouco favorecido por investimentos e políticas públicas de lazer, consegue vivenciar a cultura lúdica nos limitados espaços que as escolas, a SAB, a Igreja, as ruas e quando pago, no Clube dos Taxistas e no Clube dos Sargentos e Cabos da Polícia oferecem. 
As condições de infraestrutura são precárias, havendo muitos terrenos baldios cortados pelo esgoto a céu aberto e muitos animais soltos no bairro, podendo provocar zoonoses e mesmo acidentes.

Não se pode calar diante das autoridades e é importante sim a reivindicação por melhorias relacionadas à área de lazer. Buscar o compromisso público através de possibilidades de construções e realizações que incentivem práticas saudáveis de lazer, capazes de contribuírem para o crescimento e desenvolvimento humano e social e, consequentemente, para a qualidade de vida (Chemin, 2007).

É necessário uma atenção maior por parte dos órgãos públicos, muitas promessas já foram feitas, segundo a atual presidente do Clube de Mães, mas passada a eleição, fica tudo do mesmo jeito. A única saída que encontram é fazer o requerimento de um ônibus ao CRAS (Centro de Referência de Assistência Social) e ir passear em clubes nas proximidades da cidade.

Através da SAB, da Associação de Moradores e do Clube de Mães, o bairro já conseguiu alguns espaços para os moradores, porém todos limitados por muros ou esgotos a céu aberto. Desta forma, percebese uma necessidade de um trabalho mais efetivo de conscientização dos direitos que a comunidade tem e uma articulação maior entre suas entidades representativas, já que atualmente as questões de política partidária estão separando os representantes e isso só tem trazido problemas à comunidade.

\section{Referências}

BAGRICHEVSKY, Marcos; PALMA; Alexandre; ESTEVÃO; Adriana. Análise sobre os limites da inferência causal no contexto investigativo "exercício físico e saúde". In: BAGRICHEVSKY, MARCOS; PALMA, ALEXANDRE e ESTEVÃO, ADRIANA. A Saúde em Debate na Educação Física. Blumenal:Edibes, 2003.

BRUHNS, Heloisa Turini. Introdução aos Estudos do Lazer. Campinas: UNICAMP, 1997 
CARVALHO, Yara M. Lazer e saúde: a sociedade e o social. In: MARCELLINO, Nelson Carvalho. Lazer e Sociedade - Múltiplas Relações. Campinas: Alínea, 2008.

CASTRO, Mônica da Silva. Modelo da Atividade Recreação: módulo programação. Rio de Janeiro: SESC, Departamento Nacional, 2007.

CECCIM, Ricardo Burg; BILIBIO Luiz Fernando. Singularidades da educação física na saúde. In: FRAGA, Alex Branco e WACHS, Felipe. Educação Física e Saúde Coletiva: políticas de formação e perspectivas de intervenção. Porto Alegre - RS: Editora UFRGS, 2007.

CHEMIN, Beatriz Francisca. Políticas Públicas de Lazer: o Papel dos Municípios na sua Implementação. Curitiba: Juruá, 2007.

FALCÃO, José Luiz Cirqueira; SARAIVA, Maria do Carmo (Org.). Esporte e Lazer na cidade: práticas corporais re-sigificadas. Florianópolis: Lagoa Editora, 2007.

GABRIEL, Oldrey Patrick Bittencourt. Lazer e Religião: algumas aproximações. In: MARCELLINO, Nelson Carvalho. Lazer e Sociedade - Múltiplas Relações. Campinas: Alínea, 2008.

MARCELLINO, Nelson Carvalho. Lazer e Esporte: políticas públicas. Autores Associados, 2001

Nelson Carvalho. Lazer e Educação. 12 ed. Campinas: Papirus, 2007.

Nelson Carvalho. Lazer e Sociedade - Múltiplas Relações. Campinas: Alínea, 2008.

MARIANO, Stéphanie Helena \& MARCELLINO, Nelson Carvalho. Equipamentos de lazer em cidades pequenas de região metropolitana. $R e$ vista Motriz - Equipamentos de Lazer. Rio Claro, v. 14, n. 2, p. 168-178, abr./jun. 2008 
MÜLLER, Kathia T. Organização de moradores numa perspectiva de necessidades radicais. 1992 Dissertação (Mestrado em Sociologia Política) - Universidade Federal de Santa Catarina, Florianópolis, 1992.

PINTO, Leila Mirtes Santos de Magalhães. Desafios para as Políticas Públicas de Lazer no Brasil. In: Encontro Nacional de Recreação e Lazer, 20, 2008, São Paulo. Anais... São Paulo, 1994. CD-ROM.

Leila Mirtes Santos de Magalhães. Lazer e Educação: desafios da atualidade. In MARCELLINO, Nelson Carvalho. Lazer e Sociedade - Múltiplas Relações. Campinas, SP: Editora Alínea, 2008.

PEREIRA, Luiz Carlos Bresser; GRAU, Núria Cunill (org). O público não estatal na reforma do Estado. Rio de Janeiro: Fundação Getúlio Vargas, 1999.

PREFEITURA MUNICIPAL DE CAMPINA GRANDE - Portal da Transparência. Cerca de 40 mil atendimentos pela campina bem-estar. Disponível em: <http://www.pmcg.pb.gov.br/transparencia/eixos/cidadania/14.php>. Acesso em: 15 jan 2009.

RECHIA. Simone. A Política de Lazer na Cidade: Em Pauta: "A Análise da Gestão dos Espaços em Distintas Realidades e Segmentos Populacionais. In: Encontro Nacional de Recreação e Lazer, 20.,2008. São Paulo. Anais... São Paulo, 1994. CD-ROM.

RESENDE, Lenise. "Festas Religiosas Populares". Almanaque Abril 1995 / 2001; Globinho Pesquisa. Disponível em: <http://www.lendorelendogabi.com/folclore/festas_religiosas_populares_pag4.htm>. Acesso em: 09 mai 2009.

SAMPAIO, Tânia Mara Vieira. Gênero e Lazer. In MARCELLINO, Nelson Carvalho. Lazer e Sociedade - Múltiplas Relações. Campinas, SP: Editora Alínea, 2008. 
ZINGONI, Patrícia. O lugar das famílias nas Políticas de Lazer in MARCELLINO, Nelson Carvalho. Lazer e Sociedade - Múltiplas Relações. Campinas, SP: Editora Alínea, 2008.

"Ação Escola". Disponível em: <http://www.institutoalpargatas.com. br/index.php?Projeto-Acao-Escola>. Acesso em: 17 jan 2009. 